\title{
CONCENTRATION INCREASE OF THE SINGLET-OXYGEN GENERATION QUANTUM YIELD BY AN INDOTRICARBOCYANINE DYE
}

\author{
M. P. Samtsov, ${ }^{a^{*}}$ D. S. Tarasau, ${ }^{b}$ A. S. Stasheuski, \\ K. N. Kaplevsky, ${ }^{\text {b }}$ and E. S. Voropay ${ }^{b}$
}

UDC 535.37+535.34:541.14

Regularities in the generation of singlet oxygen sensitized by the indotricarbocyanine dye $\mathrm{HITC}$ with $\mathrm{I}^{-}$and $\mathrm{ClO}_{4}{ }^{-}$ anions in highly and slightly polar solvents were studied as functions of dye concentration $\left(C_{d}\right)$. The yield of singletoxygen formation $\left(\gamma_{\Delta}\right)$ by HITC $\left(I^{-}\right)$increased in slightly polar solvents as its concentration increased. It was shown that HITC with $\mathrm{C}_{d}<10^{-7} \mathrm{M}$ in $\mathrm{CHCl}_{3}$ and $<5 \cdot 10^{-6} \mathrm{M}$ in o-dichlorobenzene with any anion was found primarily in the form of free ions. It was established that the concentration increase of singlet-oxygen generation by HITC $\left(I^{-}\right)$ was due to the heavy-atom effect of the anion as a result of their existence as contact ion pairs and an increase of the fraction of such pairs in a solution with an increased photosensitizer concentration. The quantum yield of singletoxygen formation for $\mathrm{HITC}$ with $\mathrm{ClO}_{4}^{-}$counterion was stable in various solvents as $\mathrm{C}_{d}$ was varied over a wide range.

Keywords: indotricarbocyanine dyes, ion pair, photophysical properties, singlet oxygen, concentration regularities.

Introduction. Cationic polymethine dyes (PDs) are widely used in several areas of human activity [1]. Indolenine PDs are used as biological fluorescence probes for various purposes [2-5]. Dyes with absorption and emission bands in the near-IR region are promising as photosensitizers for cancer photochemotherapy and diagnostics [6-16]. It must be considered for all dye applications that part of the excitation energy during light absorption is expended on the sensitization of singletoxygen $\left({ }^{1} \mathrm{O}_{2}\right)$ formation. This process in oxygen-saturated solutions is responsible for PD photodestruction [17, 18]. The efficiency of PDs as photosensitizers depends mainly on their ability for photo-induced ${ }^{1} \mathrm{O}_{2}$ generation [11]. The effect of ionic equilibria on the efficiency of ${ }^{1} \mathrm{O}_{2}$ generation by PDs has not been sufficiently studied despite much research on PD photophysical properties in various solvents [17-20]. Such research is important because indotricarbocyanine dyes in cancer cells are localized in regions of low dielectric permeability primarily as contact ion pairs $[12,15]$.

The present work analyzed phosphorescence parameters of ${ }^{1} \mathrm{O}_{2}$ and reports results from photosensitization of oxygen by the indotricarbocyanine dye $\mathrm{HITC}$ with $\mathrm{I}^{-}$and $\mathrm{ClO}_{4}^{-}$anions in highly and slightly polar solvents as its concentration varied over a wide range.

Experimental. We studied 1,3,3; $1^{\prime}, 3^{\prime}, 3^{\prime}$-hexamethyl-2,2'-indotricarbocyanine (HITC) with perchlorate $\left(\mathrm{ClO}_{4}^{-}\right)$and iodide $\left(\mathrm{I}^{-}\right)$anions. The properties of this dye are rather well studied. In particular, the mechanism of oxygen photosensitization by this compound was established [21]. The purity was determined using an Agilent 1200 Rapid Resolution LC liquid chromatograph with an Agilent 6410 Triple Quad mass detector and diode-matrix detector. The LC-MS measurements found that the studied dyes were chemically pure. $\mathrm{EtOH}$, o-dichlorobenzene (DCB), and $\mathrm{CHCl}_{3}(\mathrm{CF})$ were used as the solvents and were purified before use by standard methods [22].

Fluorescent characteristics of the dyes were recorded using a Fluorolog spectrofluorimeter; electronic absorption spectra, PV 1251B (Solar) and MC 122 (Proscan) spectrophotometers. Measurements were made in cuvettes from 50 to $0.13 \mathrm{~mm}$ thick in order to vary the solution dye concentration in the range $10^{-8}-10^{-3} \mathrm{M}$. The sample solutions were always thermostatted because the PD luminescent characteristics were dependent on temperature.

Luminescence of ${ }^{1} \mathrm{O}_{2}$ near $1270 \mathrm{~nm}$ was recorded using an apparatus fabricated at the Laboratory of Molecular Photonics, Institute of Physics, NASB [23]. Dyes were excited using radiation from a semi-conducting laser with $\lambda=667 \mathrm{~nm}$.

\footnotetext{
${ }^{*}$ To whom correspondence should be addressed.
}

${ }^{a}$ A. N. Sevchenko Institute of Applied Physical Problems, Belarusian State University, 7 Kurchatov Str., 220064, Minsk, Belarus; e-mail: samtsov@bsu.by; ${ }^{b}$ Belarusian State University, Minsk; ${ }^{\mathrm{c} B}$. I. Stepanov Institute of Physics, National Academy of Sciences of Belarus, Minsk; e-mail: a.stasheuski@ifanbel.bas-net.by. Translated from Zhurnal Prikladnoi Spektroskopii, Vol. 81, No. 2, pp. 219-227, March-April, 2014. Original article submitted December 3, 2013. 
Table 1. Spectral and Luminescence Properties of HITC Dye with $\mathrm{I}^{-}$and $\mathrm{ClO}_{4}^{-}$Counterions

\begin{tabular}{|c|c|c|c|c|c|c|c|c|}
\hline Dye & $C_{\mathrm{d}}, \mathrm{M}$ & $\lambda_{\mathrm{abs}}^{\max }, \mathrm{nm}$ & $\Delta \lambda_{\mathrm{abs}}, \mathrm{nm}$ & $\lambda_{\mathrm{fl}}^{\max }, \mathrm{nm}$ & $\Delta \lambda_{\mathrm{fl}}, \mathrm{nm}$ & $\begin{array}{c}\varepsilon \cdot 10^{-5} \\
\mathrm{M}^{-1} \cdot \mathrm{cm}^{-1}\end{array}$ & $\varphi$ & $\tau, \mathrm{ns}$ \\
\hline \multicolumn{9}{|c|}{$\mathrm{CHCl}_{3}$} \\
\hline $\operatorname{HITC}\left(\mathrm{I}^{-}\right)$ & $10^{-8}$ & 757 & 45 & 783 & 49 & 3.7 & 0.41 & 1.6 \\
\hline $\operatorname{HITC}\left(\mathrm{I}^{-}\right)$ & $5 \cdot 10^{-6}$ & 754 & 62 & 786 & 53 & 2.2 & 0.31 & 1.2 \\
\hline $\operatorname{HITC}\left(\mathrm{ClO}_{4}^{-}\right)$ & $10^{-8}$ & 757 & 45 & 783 & 49 & 4.0 & 0.41 & 1.6 \\
\hline $\operatorname{HITC}\left(\mathrm{ClO}_{4}^{-}\right)$ & $5 \cdot 10^{-6}$ & 754 & 65 & 785 & 54 & 2.3 & 0.37 & 1.5 \\
\hline \multicolumn{9}{|c|}{ Dichlorobenzene } \\
\hline HITC(I') & $10^{-7}$ & 768 & 48 & 796 & 46 & 2.9 & 0.42 & 2.0 \\
\hline $\operatorname{HITC}\left(\mathrm{I}^{-}\right)$ & $10^{-4}$ & 767 & 53 & 798 & 50 & 2.4 & 0.28 & 1.6 \\
\hline $\operatorname{HITC}\left(\mathrm{ClO}_{4}^{-}\right)$ & $10^{-7}$ & 768 & 48 & 796 & 46 & 2.9 & 0.43 & 2.1 \\
\hline $\operatorname{HITC}\left(\mathrm{ClO}_{4}^{-}\right)$ & $10^{-4}$ & 766 & 53 & 798 & 51 & 2.4 & 0.40 & 2,1 \\
\hline \multicolumn{9}{|c|}{$\mathrm{EtOH}$} \\
\hline $\operatorname{HITC}\left(\mathrm{I}^{-}\right)$ & $10^{-7}$ & 742 & 53 & 773 & 48 & 2.5 & 0.28 & 1.4 \\
\hline $\operatorname{HITC}\left(\mathrm{I}^{-}\right)$ & $5 \cdot 10^{-5}$ & 742 & 53 & 773 & 48 & 2.5 & 0.28 & 1.4 \\
\hline $\operatorname{HITC}\left(\mathrm{ClO}_{4}^{-}\right)$ & $10^{-7}$ & 742 & 53 & 773 & 48 & 2.5 & 0.28 & 1.4 \\
\hline $\operatorname{HITC}\left(\mathrm{ClO}_{4}^{-}\right)$ & $5 \cdot 10^{-5}$ & 742 & 53 & 773 & 48 & 2.5 & 0.28 & 1.4 \\
\hline
\end{tabular}

Note. $\lambda_{\mathrm{abs}}^{\max }$ and $\lambda_{\mathrm{fl}}^{\max }$ are the position of absorption and fluorescence spectra maxima; $\Delta \lambda_{\mathrm{abs}}$ and $\Delta \lambda_{\mathrm{fl}}$, absorption and fluorescence spectra half-widths; $\varepsilon$, molar absorption coefficient; and $\tau$, fluorescence lifetime.

The measurement procedure was described in detail [20]. The quantum yield of ${ }^{1} \mathrm{O}_{2}$ formation $\left(\gamma_{\Delta}\right)$ was determined by a relative method. The standard was 5,10,15,20-tetrakis(4-N-methylpyridyl)porphyrin in $\mathrm{EtOH}\left(\gamma_{\Delta}=0.74 \pm 0.05\right)$. It is noteworthy that the ${ }^{1} \mathrm{O}_{2}$ lifetime was determined during measurements with photosensitization by standards and test compounds. It was $12 \pm 1 \mu \mathrm{s}$ for standards in EtOH; $60 \pm 2 \mu \mathrm{s}$, in DCB; and $248 \pm 6 \mu \mathrm{s}$, in CF.

Results and Discussion. It was found that the quantum yields for ${ }^{1} \mathrm{O}_{2}$ formation were identical $\left(\gamma_{\Delta}=0.006 \pm 0.001\right)$ and the phosphorescence lifetime of ${ }^{1} \mathrm{O}_{2}$ was $12 \pm 1 \mu \mathrm{s}$ in EtOH solutions as the dye concentration with any counterion varied in the range $10^{-7}-10^{-5} \mathrm{M}$ (Fig. 1, curve 3). Dye absorption spectra with the different anions in EtOH agreed in shape and position over the whole concentration range with a constant molar absorption coefficient. Fluorescence spectra, quantum yields, and fluorescence lifetimes and polarizations for dye solutions in $\mathrm{EtOH}$ agreed for both cationic analogs and remained constant in this concentration range (Table 1). The dye fluorescence decay kinetics in EtOH were single exponential. Fluorescence spectra were independent of the exciting wavelength. The excitation fluorescence spectra did not change with recording wavelength. Their shape agreed with the dye absorption spectra.

The quantity $\gamma_{\Delta}$ increased significantly as the concentration varied in the range $10^{-7}-10^{-5} \mathrm{M}$ for dye with $\Gamma^{-}$anion in DCB or CF, in contrast with highly polar EtOH. The quantum yield for ${ }^{1} \mathrm{O}_{2}$ formation for HITC $(\Gamma)$ in $\mathrm{CF}$ increased smoothly by about an order of magnitude from $0.014 \pm 0.002$ for $C_{\mathrm{d}}=1.1 \cdot 10^{-7} \mathrm{M}$ to $0.10 \pm 0.01$ for $C_{\mathrm{d}}=7.7 \cdot 10^{-6} \mathrm{M}$ (Fig. 1, curve 1). The ${ }^{1} \mathrm{O}_{2}$ phosphorescence lifetime in this dye concentration range was $248 \pm 6 \mu$ s. The enhanced efficiency of ${ }^{1} \mathrm{O}_{2}$ generation as the photosensitizer concentration increased was accompanied by a drop of its fluorescence quantum yield from 0.37 to 0.30 (curve 4) and also a decrease of the fluorescence lifetime from 1.6 to $1.2 \mathrm{~ns}$ (Table 1). Increasing the photosensitizer further to $5 \cdot 10^{-5} \mathrm{M}$ decreased the ${ }^{1} \mathrm{O}_{2}$ lifetime to $229 \pm 6 \mu$ s and its formation quantum yield to $\gamma_{\Delta}=0.09 \pm 0.01$.

The ${ }^{1} \mathrm{O}_{2}$ formation quantum yield for dye with $\mathrm{I}^{-}$in $\mathrm{CF}$ increased smoothly with increasing concentration. The concentration dependence in slightly polar but more viscous DCB differed by the presence of a section of relatively small $\gamma_{\Delta}$ changes from 0.005 to 0.009 in the concentration range $1.1 \cdot 10^{-7}-5 \cdot 10^{-6} \mathrm{M}$ (Fig. 3, curve 1 ). The quantity $\gamma_{\Delta}$ increased by almost an order of magnitude from 0.009 to 0.076 as the concentration increased to $5.7 \cdot 10^{-5} \mathrm{M}$. The ${ }^{1} \mathrm{O}_{2}$ phosphorescence 


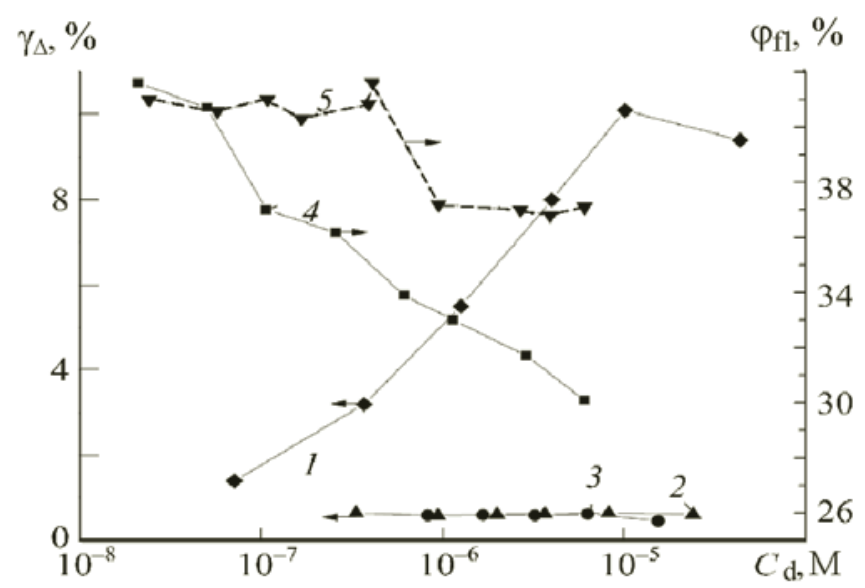

Fig. 1. Quantum yields for singlet-oxygen formation (1-3) and fluorescence $(4,5)$ in $\mathrm{EtOH}$ (3) and $\mathrm{CHCl}_{3}(1,2,4,5)$ as functions of HITC dye concentration with $\mathrm{I}^{-}(1,3,4)$ and $\mathrm{ClO}_{4}^{-}$ $(2,5)$ anions.

lifetime remained constant at $60 \pm 2 \mu \mathrm{s}$ as the dye concentration varied from $10^{-7}$ to $1.2 \cdot 10^{-5} \mathrm{M}$. The ${ }^{1} \mathrm{O}_{2}$ lifetime decreased to $49 \pm 2 \mu$ s at higher concentrations $\left(5.7 \cdot 10^{-5} \mathrm{M}\right)$. The enhanced ${ }^{1} \mathrm{O}_{2}$ generation efficiency upon increasing the photosensitizer concentration was accompanied by a drop in its fluorescence quantum yield from 0.42 to 0.28 (curve 3 ).

The increased ${ }^{1} \mathrm{O}_{2}$ formation quantum yield in slightly polar solvents was found only for dye with $\mathrm{I}^{-}$counterion. The ${ }^{1} \mathrm{O}_{2}$ formation quantum yield in the range $C_{\mathrm{d}}=1.1 \cdot 10^{-7}-2 \cdot 10^{-5} \mathrm{M}$ for the cationic analog with $\mathrm{ClO}_{4}^{-}$counterion was constant at $0.006 \pm 0.001$ in $\mathrm{CF}$ and $0.005 \pm 0.001$ in DCB. The fluorescence quantum yield decreased from 0.41 to 0.37 and the fluorescence lifetime decreased from 1.6 to $1.5 \mathrm{~ns}$ as the concentration of dye with $\mathrm{ClO}_{4}^{-}$counterion in $\mathrm{CF}$ increased (Fig. 1, curve 5).

The used apparatus enabled the dye spectral properties to be recorded over the broader concentration range of $10^{-8}-10^{-4} \mathrm{M}$. The shape and position of the dye absorption and fluorescence spectra with the different counterions agreed and the quantum yields and fluorescence lifetimes practically coincided at low concentrations $\left(\sim 10^{-8} \mathrm{M}\right)$ in slightly polar CF or DCB (Table 1). The ${ }^{1} \mathrm{O}_{2}$ generation quantum yields for the dye iodide and perchlorate in slightly polar $\mathrm{CF}$ and DCB and in polar EtOH were similar. The spectral characteristics changed significantly as the dye concentration increased in the slightly polar solvents for dye with both counterions. The maximum of the long-wavelength band shifted to shorter wavelength, its half-width increased, and the molar absorption coefficient decreased in dye absorption spectra as the concentration increased in both slightly polar solvents (Figs. 2, 4, 5). Thus, the absorption spectrum half-width for HITC( $\Gamma^{-}$) in CF increased from 45 to $62 \mathrm{~nm}$ and the molar absorption coefficient decreased from $3.7 \cdot 10^{5}$ to $2.2 \cdot 10^{5} \mathrm{M}^{-1} \cdot \mathrm{cm}^{-1}$ as $C_{\mathrm{d}}$ increased (Fig. 2). The absorption spectrum half-width increased from 45 to $65 \mathrm{~nm}$ and the absorption coefficient decreased from $4.0 \cdot 10^{5}$ to $2.3 \cdot 10^{5}$ $\mathrm{M}^{-1} \cdot \mathrm{cm}^{-1}$ for HITC $\left(\mathrm{ClO}_{4}^{-}\right)$(Fig. 5). The change of dye absorption spectra with concentration was accompanied by a change of the fluorescence spectrum (Fig. 6). The strongest changes for both dye cationic analogs were observed in CF (Table 1). Thus, the fluorescence spectrum half-width for HITC(I- $)$ in CF increased from $49 \mathrm{~nm}\left(C_{\mathrm{d}}=10^{-8} \mathrm{M}\right)$ to $53 \mathrm{~nm}\left(C_{\mathrm{d}}=5 \cdot 10^{-6} \mathrm{M}\right)$ and increased from 49 to $54 \mathrm{~nm}$ for dye with $\mathrm{ClO}_{4}^{-}$counterion in this same concentration range. The concentration changes of the spectral characteristics were less significant in DCB. Moreover, analogous spectral changes were observed for both studied dyes with $\mathrm{I}^{-}$and $\mathrm{ClO}_{4}^{-}$anions.

The observed functions of ${ }^{1} \mathrm{O}_{2}$ formation efficiency in slightly polar solvents were reversible as the concentration changed. The ${ }^{1} \mathrm{O}_{2}$ formation quantum yields agreed if the solution concentration was restored by increasing the $\operatorname{HITC}\left(\mathrm{I}^{-}\right)$ concentration in $\mathrm{CF}$ or evaporating solvent at room temperature and by diluting a more concentrated solution to the initial concentration. The shape and position of the absorption and fluorescence spectra and the dye fluorescence lifetime and quantum yield were restored.

It is noteworthy that the studied compounds were highly pure (>99\%) according to LC-MS measurements. Uncontrolled impurities in the solvents did not affect the studied parameters because the concentration changes of the dye spectral and photophysical properties in the solutions were reversible. Therefore, it could be confirmed that the observed features were due to specific effects of the solvent polarity on the dye properties. 


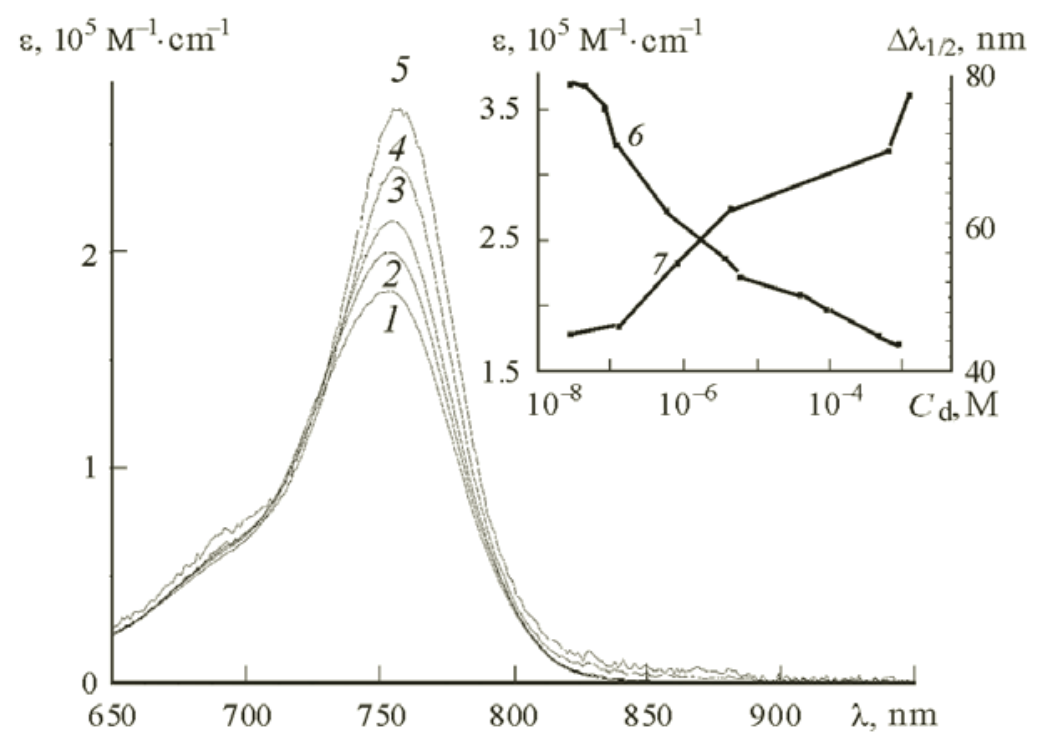

Fig. 2. Absorption spectra of $\mathrm{HITC}\left(\mathrm{I}^{-}\right)$dye in $\mathrm{CHCl}_{3}$ at concentrations $1.0 \cdot 10^{-5}(1), 5.3 \cdot 10^{-6}$ (2), 2.6 $10^{-6}(3), 6.3 \cdot 10^{-7}(4)$, and 3.3 $10^{-7} \mathrm{M}(5)$; in the inset, molar absorption coefficient (6) and absorption spectrum half-width (7) as functions of dye concentration.

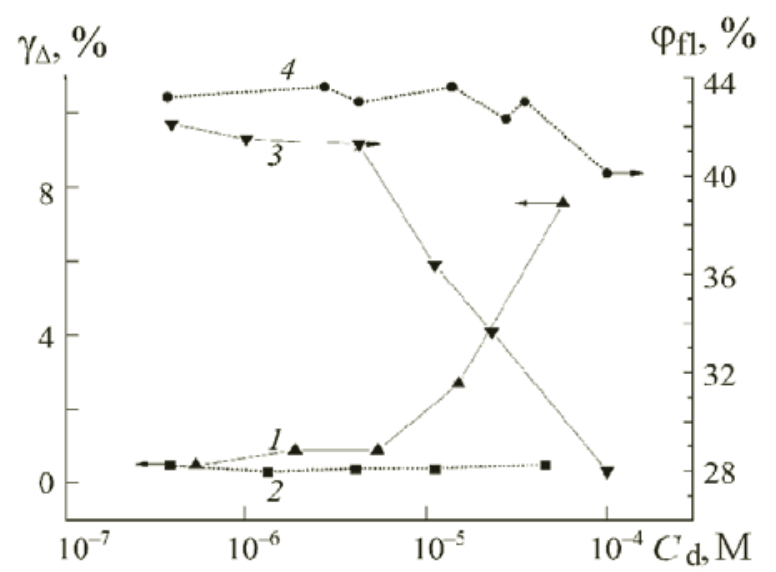

Fig. 3. Quantum yields for singlet-oxygen formation by $\operatorname{HITC}(\Gamma)(1)$ and $\operatorname{HITC}\left(\mathrm{ClO}_{4}^{-}\right)(2)$ and fluorescence of $\mathrm{HITC}\left(\mathrm{I}^{-}\right)(3)$ and $\mathrm{HITC}\left(\mathrm{ClO}_{4}^{-}\right)$(4) in dichlorobenzene as functions of dye concentration.

The facts that the concentration in polar EtOH did not affect the dye spectral properties with any counterion and the constant quantum yield and fluorescence lifetime indicated that each dye in this solvent had only one absorbing and fluorescing center. The constant ${ }^{1} \mathrm{O}_{2}$ formation quantum yield in polar $\mathrm{EtOH}$ with changing photosensitizer concentration and the agreement of $\gamma_{\Delta}$ values for dyes with $\mathrm{I}^{-}$and $\mathrm{ClO}_{4}^{-}$counterions indicated that $\mathrm{I}^{-}$did not act as a heavy atom at the used concentrations. Such behavior agreed with previous results [21] where the photophysical parameters of this dye changed only at concentrations $>5 \cdot 10^{-3} \mathrm{M}$ after adding additional $\mathrm{KI}$ to the solution. The identical spectral and luminescence characteristics of the cationic dye analogs with different counterions were consistent with the dissociation of these compounds into ions in polar solvents $[18,19]$.

Changes of the photophysical properties of the iodide upon increasing the concentration in slightly polar solvents in addition to the spectral characteristics of photosensitizers with $\mathrm{I}^{-}$and $\mathrm{ClO}_{4}^{-}$counterions indicated that the system was nonuniform under such conditions. The correspondence in concentration ranges at which the ${ }^{1} \mathrm{O}_{2}$ formation quantum yield by the dye iodide and its fluorescence quantum yield and lifetime changed was interesting. These concentration functions were 


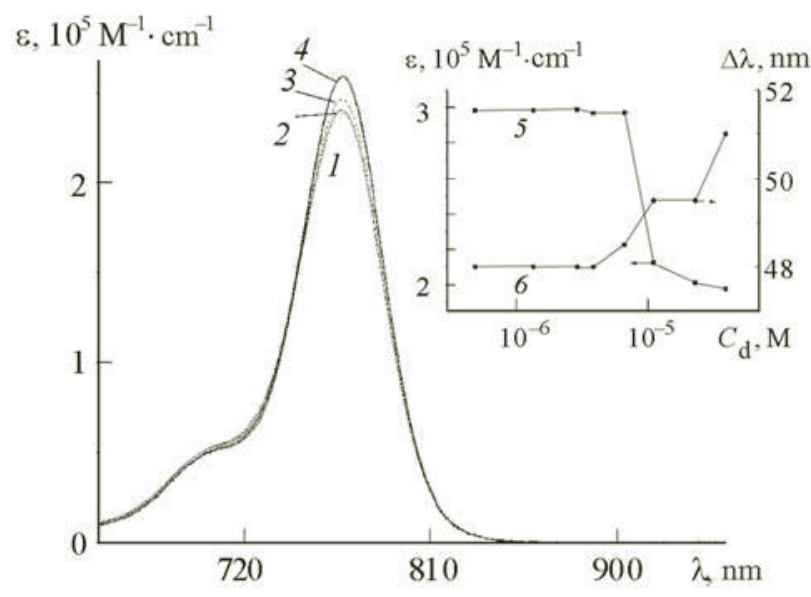

Fig. 4. Absorption spectra of $\mathrm{HITC}\left(\mathrm{I}^{-}\right)$in dichlorobenzene at concentrations $3.9 \cdot 10^{-5}(1)$, $2.3 \cdot 10^{-5}(2), 1.1 \cdot 10^{-5}(3)$, and $4.9 \cdot 10^{-7} \mathrm{M}(4)$; in the inset, molar absorption coefficient (5) and absorption spectrum half-width (6) as functions of dye concentration.

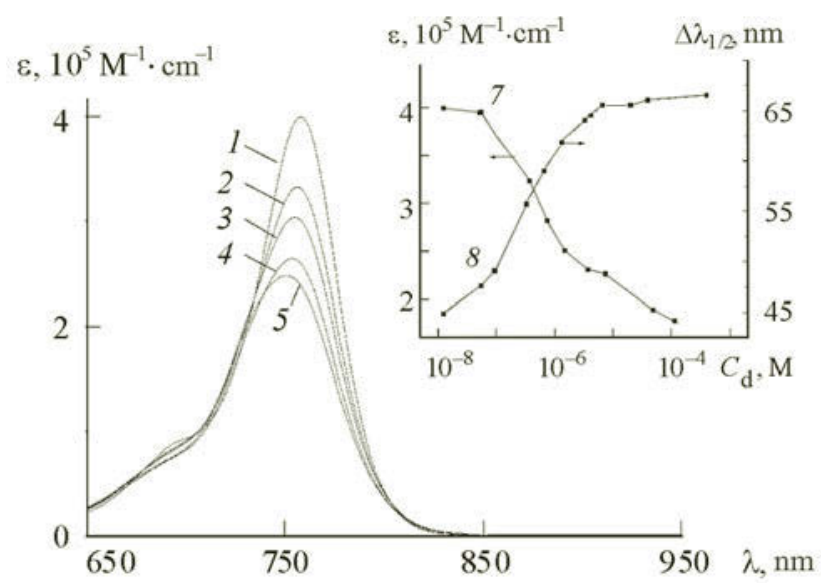

Fig. 5. Absorption spectra of $\mathrm{HITC}\left(\mathrm{ClO}_{4}^{-}\right)$in $\mathrm{CHCl}_{3}$ at concentrations $0.9 \cdot 10^{-7}(1), 3.3 \cdot 10^{-7}$ (2), $6.6 \cdot 10^{-7}(3), 1.3 \cdot 10^{-6}(4)$, and $3.3 \cdot 10^{-6} \mathrm{M}(5)$; in the inset, molar absorption coefficient (7) and absorption spectrum half-width (8) as functions of concentration.

accompanied by changes of the dye spectral characteristics. The quantity $\gamma_{\Delta}$ increased smoothly, the absorption maximum shifted and its half-width increased in concert, and the molar absorption coefficient decreased as the dye iodide concentration in CF increased. It is noteworthy that the fluorescence quantum yield fell from 0.41 to 0.31 for dye iodide in CF and from 0.41 to 0.37 for dye perchlorate as the concentration in CF increased. The spectral characteristics of the studied compounds and their fluorescence quantum yields practically did not change in more viscous DCB in the region where the change of $\gamma_{\Delta}$ was insignificant. The increase in the ${ }^{1} \mathrm{O}_{2}$ formation quantum yield from 0.009 to 0.79 for the iodide as the concentration changed in the range $5 \cdot 10^{-6}-5.7 \cdot 10^{-5} \mathrm{M}$ corresponded with a simultaneous decrease of the dye fluorescence quantum yield from 0.42 to 0.28 . Such agreement with the dye concentration of the changes of spectral parameters, fluorescence quantum yield, and ${ }^{1} \mathrm{O}_{2}$ formation quantum yield were consistent with the general nature of the observed concentration features. Therefore, the results in slightly polar solvents suggested that the dye molecules existed in two forms with different photophysical properties. It could be assumed that molecular associates formed in slightly polar solvents as the concentration increased [25]. However, the following experimental results did not agree with this assumption. Associates of the studied compounds do not fluoresce [25]. However, the absorption and fluorescence spectra changed with concentration. Therefore, both centers present in solution exhibited fluorescence. Furthermore, the ${ }^{1} \mathrm{O}_{2}$ formation quantum yield increased as a function of dye concentration only for the iodide. Association of dye molecules was not realistic for the instance where analogous spectral changes that were comparable in magnitude were observed for both compounds as the concentration increased. 


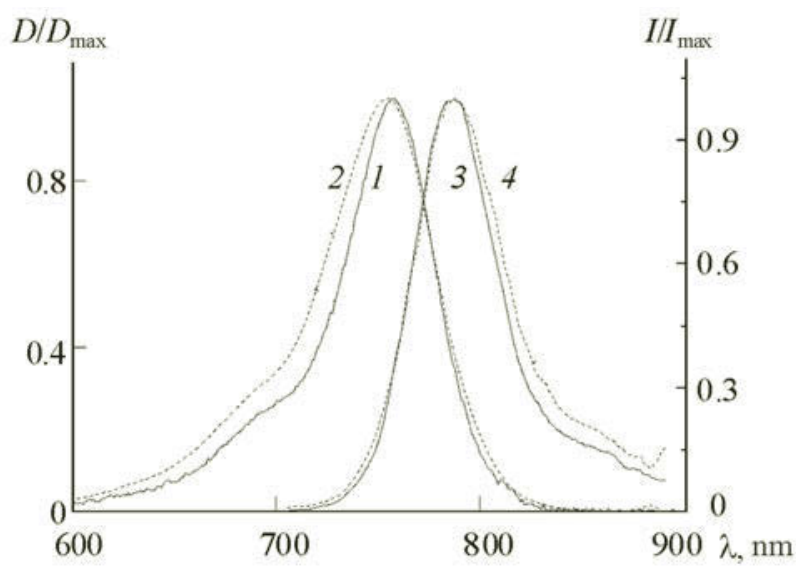

Fig. 6. Absorption $(1,2)$ and fluorescence spectra for $\lambda_{\mathrm{ex}}=695 \mathrm{~nm}(3,4)$ of $\operatorname{HITC}(\Gamma)$ in $\mathrm{CHCl}_{3}$ at concentrations $5.0 \cdot 10^{-7}(1,3)$ and $5.9 \cdot 10^{-6} \mathrm{M}(2,4)$.

The mechanism for oxygen sensitization by the studied dyes was non-radiative energy transfer from the sensitizer in the triplet state [21]. The oxygen diffusion rate for most organic solvents at room temperature is such that the ${ }^{1} \mathrm{O}_{2}$ generation quantum efficiency for complicated organic molecules practically coincides with the yield into the triplet state [26-28]. Therefore, the value of $\gamma_{\Delta}$ is determined by the yield of the dye molecule into the triplet state. The presence of heavy atoms in the anion even at low concentrations can enhance intersystem crossing if the cation and anion are in close proximity (as a contact pair). Thus, it was found $[29,30]$ that the yield of molecules into the triplet state was greater for PDs with $\mathrm{I}^{-}$anion in a slightly polar solvent.

According to our results, the ${ }^{1} \mathrm{O}_{2}$ formation quantum yield increased approximately as much as the fluorescence yield decreased in both slightly polar solvents for the dye with $\mathrm{I}^{-}$anion at high concentrations. It should be considered that the ${ }^{1} \mathrm{O}_{2}$ formation yield did not depend on concentration for the dye with perchlorate anion and the changes of the fluorescence quantum yield were significantly smaller. However, the spectral characteristics of both dyes changed to the same degree and in the same concentration range. Such correspondence was possible if the probability of intersystem crossing from the first excited singlet state of the dye with $\mathrm{I}^{-}$anion into the triplet state increased.

The coincidence of the spectral and luminescence characteristics of dyes with different counterions at low concentrations in CF or DCB and the similar ${ }^{1} \mathrm{O}_{2}$ formation quantum yields for both dyes with $\gamma_{\Delta}$ in polar EtOH indicated that the dye anion under such conditions did not affect the molecular photophysical properties. Thus, dye molecules at low concentrations in slightly polar solvents (CF or DCB) and in EtOH were well separated, i.e., free ions. Moreover, the probability that the dye cation and anion would approach each other at a distance short enough that the heavy anion affected the probability of intersystem crossing in the dye cation increased as a result of Brownian motion as the concentration increased ( $>10^{-7} \mathrm{M}$ in $\mathrm{CF} ;>5 \cdot 10^{-6} \mathrm{M}$ in DCB). The heavy-atom effect could be manifested if the distance between the ions was extremely short. This was consistent with previous results [31] where the yield of molecules in the triplet state increased significantly ( $>30$ times) for symmetric dyes if an $\mathrm{H}$ atom in the polymethine chain was replaced by $\mathrm{I}$. The population of the triplet state increased only by $\sim 3$ times if an F atom was replaced by the same I in the terminal groups of the dye cation. The characteristic distance from the anion to the polymethine chain could be estimated at several Ångstroms, i.e., where the dye existed in solution as contact ion pairs, based on these data. Therefore, the concentration enhancement of ${ }^{1} \mathrm{O}_{2}$ formation in slightly polar solutions of $\mathrm{HITC}\left(\mathrm{I}^{-}\right)$was due to the manifestation of a heavy-anion effect for molecules in contact ion pairs and an increase of the fraction of such pairs as the concentration increased.

The decreased ${ }^{1} \mathrm{O}_{2}$ lifetime for dye with $\Gamma^{-}$at concentrations $>10^{-5} \mathrm{M}$ in both slightly polar solvents and the drop of ${ }^{1} \mathrm{O}_{2}$ formation quantum yield in $\mathrm{CF}$ were due to the fact that these dyes were effective ${ }^{1} \mathrm{O}_{2}$ quenchers [32]. The Stern-Volmer equation was used to estimate the ${ }^{1} \mathrm{O}_{2}$ quenching rate constant $k_{\mathrm{q}}$ by $\mathrm{HITC}\left(\mathrm{I}^{-}\right)$photosensitizer. The ${ }^{1} \mathrm{O}_{2}$ lifetimes were calculated from the change of dye concentration as $k_{\mathrm{q}}=6.9 \cdot 10^{6} \mathrm{M}^{-1} \cdot \mathrm{s}^{-1}$ for CF and $6.5 \cdot 10^{7} \mathrm{M}^{-1} \cdot \mathrm{s}^{-1}$ for DCB. The resulting $k_{\mathrm{q}}$ were of the same order of magnitude as the value $7.6 \cdot 10^{7} \mathrm{M}^{-1} \cdot \mathrm{s}^{-1}$ reported for HITC perchlorate [32].

The fact that the studied compounds were present in slightly polar solvents as two ionic forms was unexpected. This was due to the fact that it was established earlier $[18,19]$ that $\mathrm{HITC}\left(\mathrm{I}^{-}\right)$in $\mathrm{CF}$ or DCB existed exclusively as contact ion pairs. 
However, these studies used dye concentrations $10^{-6}-10^{-5} \mathrm{M}$ and the properties were not analyzed as the concentration changed over a wider range. Therefore, the features established in the present work turned out to be unnoticed in our earlier research.

Conclusions. Concentration enhancement of ${ }^{1} \mathrm{O}_{2}$ formation in slightly polar solvents by $\operatorname{HITC}\left(\mathrm{I}^{-}\right)$was due to molecules in contact ion pairs, the increased fraction of such pairs with increased concentration, and the manifestation of a heavy-anion effect. HITC molecules in CF at $<10^{-7} \mathrm{M}$ and in DCB at $<5 \cdot 10^{-6} \mathrm{M}$ existed primarily as free ions. HITC in CF at concentrations $10^{-7}-7.7 \cdot 10^{-6} \mathrm{M}$ and in $\mathrm{DCB}$ at $5.2 \cdot 10^{-7}-1.6 \cdot 10^{-5} \mathrm{M}$ existed as mixtures of free ions and contact pairs and at higher concentrations as contact ion pairs. The fluorescence quantum yield and lifetime for dyes with any counterion in contact ion pairs were less than the corresponding parameters of free ions. The stability of $\gamma_{\Delta}$ for dye with $\mathrm{ClO}_{4}^{-}$counterion in various solvents as the concentration varied over a wide range enabled this compound to be considered a standard photosensitizer for determining the ${ }^{1} \mathrm{O}_{2}$ formation yield for compounds that absorb in the near-IR region. Absorption and fluorescence spectra of various ionic forms of HITC in CF and DCB had similar parameters. Therefore, ionic equilibria of such compounds cannot be established by analyzing only spectral characteristics. Thus, further research is required.

\section{REFERENCES}

1. A. Mishra, R. K. Behera, P. K. Behera, B. K. Mishra, and G. B. Behera, Chem. Rev., 100, 1973 (2000).

2. P. Fortina, K. Delgrosso, T. Sakazume, R. Santacroce, S. Moutereau, H. J. Su, D. Graves, S. McKenzie, and S. Surrey, Eur. J. Hum. Genet., 8, 884-894 (2000).

3. X. Michalet, S. Weiss, and M. Jaeger, Chem. Rev., 106, 1785-1813 (2006).

4. A. Okamoto, Chem. Soc. Rev., 40, 5815-5828 (2011).

5. M. Levitus and S. Ranjit, Q. Rev. Biophys., 44, 123-151 (2011).

6. A. R. Oseroff, G. Ara, D. Ohuoha, J. Aprille, J. C. Bommer, M. L. Yarmush, J. Foley, and L. Cincotta, Photochem. Photobiol., 46, 83-96 (1987).

7. G. S. Lipshutz, D. J. Castro, R. E. Saxton, R. P. Haugland, and J. Soudant, Laryngoscope, 104, 996-1002 (1994).

8. D. A. Bellnier, W. R. Potter, L. A. Vaughan, T. M. Sitnik, J. C. Parsons, W. R. Greco, J. Whitaker, P. Johnson, and B. W. Henderson, Photochem. Photobiol., 62, 896-905 (1995).

9. E. S. Voropay, M. P. Samtsov, A. P. Lugovsky, E. A. Zhavrid, E. N. Alexandrova, Yu. P. Istomun, and I. N. Zhuravkin, Exp. Oncol., 19, 56-60 (1997).

10. S. I. Schastak, V. Enzmann, A. Jngel, E. A. Zhavrid, E. N. Alexandrova, E. S. Voropay, M. P. Samtsov, A. P. Lugovskiy, and P. Wiedemann, Laser Medizin., 13, 50-54 (1997).

11. E. Delaey, F. Van Laar, D. De Vos, A. Kamuhabwa, P. Jacobs, and P. De Witte, J. Photochem. Photobiol., B, 55, 27-36 (2000).

12. E. S. Voropay, M. P. Samtsov, K. N. Kaplevskii, and A. A. Lugovskii, Zh. Prikl. Spektrosk., 71, No. 2, 166-172 (2004).

13. Y. P. Istomin, E. N. Alexandrova, E. A. Zhavrid, M. P. Samtsov, K. N. Kaplevsky, and A. A. Lugovsky, Exp. Oncol., 28, 80-82 (2006).

14. M. P. Samtsov, E. S. Voropay, K. N. Kaplevskii, D. G. Mel'nikov, L. S. Lyashenko, and Yu. P. Istomin, Zh. Prikl. Spektrosk., 76, No. 4, 576-582 (2009) [J. Appl. Spectrosc., 76, No. 4, 547-553 (2009)].

15. M. P. Samtsov, E. S. Voropay, D. G. Mel'nikov, L. S. Lyashenko, A. A. Lugovskii, and Yu. P. Istomin, Zh. Prikl. Spektrosk., 77, No. 3, 438-444 (2010).

16. M. P. Samtsov, E. S. Voropay, L. S. Lyashenko, D. G. Mel'nikov, K. N. Kaplevskii, and A. P. Lugovskii, Zh. Prikl. Spektrosk., 78, No. 1, 121-127 (2011) [J. Appl. Spectrosc., 78, No. 1, 110-116 (2011)].

17. M. P. Samtsov and E. S. Voropay, Zh. Prikl. Spektrosk., 65, No. 2, 218-228 (1995).

18. M. P. Samtsov, S. A. Tikhomirov, L. S. Lyashenko, D. S. Tarasov, O. V. Buganov, V. A. Galievskii, A. S. Stashevskii, and E. S. Voropay, Zh. Prikl. Spektrosk., 80, No. 2, 177-182 (2013) [J. Appl. Spectrosc., 80, No. 2, 170-175 (2013)].

19. M. P. Samtsov, E. S. Voropay, K. N. Kaplevskii, and D. G. Mel'nikov, Zh. Prikl. Spektrosk., 75, No. 5, 684-693 (2008) [J. Appl. Spectrosc., 75, No. 5, 682-699 (2008)].

20. K. N. Kaplevskii, M. P. Samtsov, A. S. Stashevskii, V. A. Galievskii, D. S. Tarasov, and E. S. Voropay, Vestn. Beloruss. Gos. Univ., Ser. 1: Fiz., Mat., Inf., No. 2, 7-11 (2012).

21. E. S. Voropay and M. P. Samtsov, Opt. Spektrosk., 62, 64-67 (1987).

22. A. J. Gordon and R. A. Ford, A Chemist’s Companion, Wiley-Interscience, New York (1972). 
23. A. S. Stashevskii, V. A. Galievskii, and B. M. Dzhagarov, Prib. Metody Izmer., 2, No. 1, 25 (2011).

24. P. K. Frederiksen, S. P. McIlroy, C. B. Nielsen, L. Nikolajsen, E. Skvosen, M. Jorgensen, K. V. Mikkelsen, and P. R. Ogilby, J. Am. Chem. Soc., 127, 255-269 (2005).

25. A. A. Ishchenko, Structure and Spectral-Luminescent Properties of Polymethine Dyes [in Russian], Naukova Dumka, Kiev (1994).

26. D. R. Kearns, Chem. Phys., 71, 395-427 (1971).

27. A. U. Khan, J. Phys. Chem., 80, 2219-2227 (1976).

28. B. M. Dzhagarov, G. P. Gurinovich, V. E. Novichenkov, K. I. Salokhiddinov, A. M. Shul'ga, and V. A. Ganzha, Khim. Fiz., 6, No. 8, 1069-1078 (1987).

29. A. S. Tatikolov, L. A. Shvedova, N. A. Derevyanko, A. A. Ishchenko, and V. A. Kuzmin, Chem. Phys. Lett., 190, No. 3-4, 291-297 (1992).

30. A. V. Odinokov, M. V. Bazilevskii, N. Kh. Petrov, A. K. Chibisov, and M. V. Alfimov, Khim. Vys. Energ., 44, No. 5, 408-414 (2010).

31. V. A. Kuz'min, A. P. Darmanyan, V. I. Shirokova, M. A. Al'perovich, and I. I. Levkoev, Izv. Akad. Nauk SSSR, Ser. Khim., 3, 581-586 (1978).

32. J. R. Kanofsky and P. D. Sima, Photochem. Photobiol., 71, No. 4, 361-368 (2000). 